\title{
Acute abdominal compartment syndrome in a severely burned patient: Lack of colloid fluid availability in acute resuscitation may play a role
}

\author{
S Botes, MB ChB; W G Kleintjes, MMed, FC (Plast Surg) SA, PhD; E P Kotzee, MB ChB; B Bulajic, MB ChB, FCEM (SA), MMed; \\ A Fredericks, MB ChB; J L Burke, MB ChB, DA (SA), FCA, MMed; J Buys, MB ChB, H Dip Int Med, DA (SA) \\ Western Cape Provincial Tertiary Adult Burn Unit, Division of Surgery, Tygerberg Hospital and Stellenbosch University, South Africa
}

Corresponding author:W G Kleintjes (waynekleintjes@yahoo.com)

\begin{abstract}
We report on a case in which a 27-year-old male patient sustained a significant burn injury requiring admission to the intensive care unit, with respiratory support and close haemodynamic monitoring. Owing to a lack of colloid resuscitation fluids, crystalloid fluids were used exclusively. The volume of fluid required to maintain an adequate urine output also resulted in fluid sequestration in other body compartments, eventually resulting in abdominal compartment syndrome. We believe this life-threatening complication could have been avoided had colloids been available.
\end{abstract}

SAfr J Plast Reconstr Aesthet Surg Burns 2018; (1):4-5. DOI: 10.7196/SAJPRASB.2018.v111.2

A 27-year-old male patient presented to Mitchell's Plain Hospital on 4 December 2017 with 50\% total body surface area (TBSA) burns and an inhalational injury. He was brought in by the paramedics, and no other past medical history was obtained prior to intubation for airway protection (rapid sequence intubation). Areas involved included superficial and middermal burns to his face, occiput, neck and right arm. He had mid-dermal burns to his left foot and right leg. The remainder to his back, left arm and thigh were deep dermal and full-thickness burns. His left arm had circumferential full-thickness burns, and escharotomies were performed. He had an abbreviated burn severity index of 9. His fluid requirement, according to the modified Parkland formula, was calculated as $14 \mathrm{~L}$ required in the first 24 hours, at a rate of $875 \mathrm{~mL} / \mathrm{hr}$ for the first 8 hours, then $437.5 \mathrm{~mL} / \mathrm{hr}$ for the next 16 hours. He had a full-body scrub-down, and wounds were dressed with ACTICOAT. Morphine and midazolam sedation was started as an infusion.

During the resuscitative phase, he required frequent crystalloid boluses, owing to drops in urine output and mean arterial pressures (MAPs). These were associated with increased heart rates of 130 - 145 bpm, and serum lactate of $\sim 3$. Inotropes were not needed at this stage. Albumin was also not obtainable after-hours in the unit, and therefore not given to the patient. After an $80 \mathrm{mg}$ dose of furosemide, calculated at $1 \mathrm{mg} / \mathrm{kg}$, he passed more than $2 \mathrm{~mL} / \mathrm{kg}$ urine. Furosemide is usually given half an hour after starting albumin, and in this case the rationale for giving the furosemide is not clear. At this time, he had clear air entry, with no evidence of pulmonary oedema. He was ventilating easily on lung protective settings. His acidosis improved. He did, however, receive $17 \mathrm{~L}$ of fluid in total in the first 24 hours, $3 \mathrm{~L}$ more than the calculated need.

Preoperatively he had a pH of 7.24 (from 6.9) with $\mathrm{PaCO}_{2} 7.1 \mathrm{kPa}$, $\mathrm{PO}_{2} 20.5 \mathrm{kPa}$, lactate of $3.6 \mathrm{mmol} / \mathrm{L}$ (from $>15 \mathrm{mmol} / \mathrm{L}$ ) and standard bicarbonate of $21.5 \mathrm{mmol} / \mathrm{L}$. His peak airway pressure at this point was
$28 \mathrm{cmH}_{2} \mathrm{O}$. The positive end expiratory pressure (PEEP) was $10 \mathrm{cmH}_{2} \mathrm{O}$, with tidal volumes $(\mathrm{Vt})$ of $300 \mathrm{~mL} /$ breath.

Intraoperatively, his ventilation became progressively worse. Peak airway pressures required to ventilate increased to $35 \mathrm{cmH}_{2} \mathrm{O}$, with $10 \mathrm{cmH}_{2} \mathrm{O}$ PEEP. On these settings he had Vt of $200 \mathrm{~mL}$ (less than $2.5 \mathrm{~mL} / \mathrm{kg}$ ). He was still maintaining a $\mathrm{PaO}_{2}$ of $17 \mathrm{kPa}$ on a $\mathrm{FiO}_{2} 0.54$, but had huge swings on the arterial line with a systolic pressure variation of $25 \mathrm{mmHg}$. After topping up the muscle relaxant and briefly interrupting PEEP and ventilation (i.e. at the end of expiration), the intravesical (bladder) pressure measured $36 \mathrm{mmHg}$. A diagnosis of abdominal compartment syndrome (ACS) with respiratory failure was made.

At this stage, the most appropriate treatment was deemed to be an emergency laparotomy to release the abdominal hypertension. Upon entering the peritoneal cavity, more than $2 \mathrm{~L}$ of clear peritoneal fluid gushed out of the abdomen and the small bowel. The intestines were not particularly oedematous, with no signs of ischaemia and some peristalsis still present. Upon release of the rectus sheath for the laparotomy, his ventilation improved significantly. Peak airway pressures decreased to $24 \mathrm{cmH}_{2} \mathrm{O}$, with $10 \mathrm{cmH}_{2} \mathrm{O}$ PEEP. He had a tidal volume of more than $500 \mathrm{~mL}$. His $\mathrm{PaCO}_{2}$ normalised and systolic pressure variation markedly decreased to $10 \mathrm{mmHg}$. The abdomen was left open, with an occlusive dressing applied as a Bogota bag. He was transferred to the burns intensive care unit for further management.

Intraoperative fluid given was $3 \mathrm{~L}$ of Ringer's lactate, 3 units of packed red blood cells and 2 units of fresh frozen plasma (FFP).

Postoperatively, he had worsening renal failure, evident by rising creatinine, oliguria, hyperkalaemia and acidosis. Clinically he also developed coagulopathy, evidenced by oozing from all his wound sites, which could not be quantified, because thromboelastography was unavailable. A decision was made to replace platelets and clotting factors 
in the form of cryoprecipitate/FFP. There was also evidence of sepsis, and he cultured an Aeromonas hydrophillia on his tissue culture. His screening swab on admission also revealed colonisation with methicillin-sensitive Staphylococcus aureus. Based on the Aeromonas sensitivity, meropenem was started. The patient also tested positive for HIV.

On 6 December 2017 he was referred and accepted for acute haemodialysis due to worsening renal failure, refractory acidosis and uncontrollable potassium levels. Despite these efforts, he passed away on 7 December. Of significance is that his bowel still appeared viable macroscopically.

\section{Discussion}

The most common known cause of ACS in burned patients is overresuscitation. ${ }^{[1,2]}$ Our guideline for fluid resuscitation (FR) calculation is the modified Parklands formula of $3 \mathrm{~mL} / \mathrm{kg} / \mathrm{TBSA}$. We have adopted the University of Utah protocol for FR, with some modifications, and found that its application is not always easy. ${ }^{[3]}$

Several factors play a role in successful protocol application. One main factor is repetitive education. Lack of recurrent teaching of the FR protocol has led to several incidences of poor resuscitation in our unit. Instructions on fluid adjustments to nurses have also not been consistent. Despite these problems, however, this is the first case that we have encountered. The main cause was a lack of access to colloids.

The acceptable teaching for fluid resuscitation by many is to use Ringer's lactate in the first 24 hours, and to add colloids in the second 24 hours if the FR endpoint ( $1 \mathrm{~mL} / \mathrm{kg}$ for adults) has not been reached. ${ }^{[4]}$

Our colloid regimen is adopted from Bacomo and Chung. ${ }^{[5]}$ It is an aggressive regimen of albumin administration, which, in association with furosemide helps to get rid of third-space fluid rapidly, and also to reach the FR endpoint quickly.

Although there are many authors who advocate the earlier use of a colloid, within the first 24 hours, this has not been accepted as a general rule everywhere. ${ }^{[1]}$

In general, we use albumin in the second 24 hours, if the FR endpoint has not been reached, and rarely within the first 24 hours. The protocol for using a colloid earlier is good and practical: use when the FR volume exceeds double the calculated formula volumes for more than 2 hours, or massive volumes of crystalloid are given with excessive clinical oedema, or projected total fluid need exceeds $6 \mathrm{~mL} / \mathrm{kg} / \mathrm{TBSA} / 24 \mathrm{~h}$. ${ }^{[2,3]}$

In addition to giving albumin, we would always administer furosemide, to mobilise fluid from the interstitial to the intravascular space.

A colloid trial test can be done to determine the safety of administering the colloid.

In this case, albumin was not available during the time that the patient became excessively fluid-overloaded. There was no communication to the burn specialist about the dilemma overnight. By the time the patient was in theatre the next morning, there was excessive swelling of the body.

The clinical diagnosis of ACS was suggested by the anaesthetist consultant, who noticed abnormal difficulty in ventilating the patient. The clinical suspicion was confirmed intraoperatively, and bladder pressure was $36 \mathrm{mmHg}$. Some cardiac signs of raised intra-abdominal pressure are abnormal increase in pulmonary artery pressure, central venous pressure increase, cardiac output decrease, increased heart rate, variable MAP, pulmonary artery wedge pressure increase, systemic vascular resistance increase, left ventricular end-diastolic pressure decrease and right ventricular end-diastolic pressure decrease. ${ }^{[6]}$

Respiratory changes are functional residual capacity decrease, volume decrease, peak airway pressure increase, mean airway pressure increase, plateau pressures increase, intrinsic PEEP increase, dead-space ventilation increase, pulmonary oedema increase and work of breathing increase. ${ }^{[6]}$

With the acute decompensation and difficulty in ventilating the patient, an aggressive decompression laparotomy was deemed to be the most effective treatment option. ${ }^{[7]}$ Sonar-guided needle aspiration may have been an option, but this would have required some time to find a sonar to borrow, which may have then compromised the patient.

Even though the acute ACS was diagnosed quickly, and rapid action was taken, the patient died on day 4. This pattern of deterioration after 3 days has been reported previously. ${ }^{[8]}$ ACS has a very poor prognosis, and prevention should be the main focus of burn surgeons. ${ }^{[9,10]}$

\section{Conclusion}

In conclusion, the learning points we could extract as requirements for avoiding such complications in future are:

(i) good communication between nurses, junior and senior doctors;

(ii) regular teaching about the application of the fluid resuscitation protocols;

(iii) early recognition of excessive crystalloid volumes;

(iv) the use and availability of albumin to reduce crystalloid overresuscitation;

(v) the use of other colloids if albumin is not available; and

(vi) the recording of intra-abdominal pressure daily.

Acknowledgements. None.

Author contributions. SB: drafting of the manuscript, submission of manuscript; WK: literature review, critical review; EPK: critical review; BB: drafting of the manuscript; AF: drafting of the manuscript JLB: critical review; JB: drafting of the manuscript.

Funding. None.

Conflicts of interest. None.

. Park SH, Hemilla MR, Wahl WL. Early albumin use improves mortality in difficult-to-resuscitate burn patients. J Trauma Acute Care Surg 2012;73(5):1294-1297. https://doi.org/10.1097/TA.0b013e31827019b1

2. Malbrain MLNG, De Keulenaer BL, Oda J, et al. Intra-abdominal hypertension and abdominal compartment syndrome in burns, obesity, pregnancy and general medicine. Anaesthesiol Intensive Ther 2015;47(3):228-240. https://doi.org/10.5603/AlT.a2015.0021

3. Saffle J. The phenomenon of 'fluid creep' in acute burn resuscitation. J Burn Care Res 2007;28(3):382-395. https://doi.org/10.1097/BCR.0B013E318053D3A1

4. Azzopardi EA, McWilliams B, lyer S, et al. Fluid resuscitation in adults with severe burns at risk of secondary abdominal compartment syndrome - an evidence-based systematic review. Burns 2009:35(7):911-920 https://doi.org/10.1016/j.burns.2009.03.001

5. Bacomo FK, Chung KK. A primer on burn resuscitation. J Emerg Trauma Shock 2011;4(1):109-113. https://doi. org/10.4103/0974-2700.76845

6. Christensen M, Craft J. The cardio-respiratory effects of intra-abdominal hypertension: Considerations for critical care nursing practise. Intensive Crit Care Nurs 2017:44:53-58. https://doi.org/10.1016/.iccen.2017.05.003 7. Strang SG, Van Lieshout EMM, Breederveld RS, van Waes OJ. A systematic review on intra-abdominal pressure Strang SG, Van Lieshout EMM, Breederveld RS, van Waes OJ. A systematic review on intra-abdom
in severely burned patients. Burns 2014;40(1):9-16. https://doi.org/10.1016/j.burns.2013.07.001

8. Kollias $S$, Stampolidis N, Kourakos $\mathrm{P}$, et al. Abdominal compartment syndrome in a severely burned patient. Ann Burns Fire Disasters 2015;28(1):5-8.

9. Markell $\mathrm{KW}$, White $C E$, Albrecht $\mathrm{M}$, et al. Abdominal complications after severe burns. J Am Coll Surg 2009;208(5):940-947. https://doi.org/10.1016/j.jamcollsurg.2008.12.023

10. Mbiine R, Alenyo R, Kobusingye $\mathrm{O}$, et al. Intra-abdominal hypertension in severe burns: Prevalence, incidence and mortality in a sub-Saharan African hospital. Int J Burn Trauma 2017;7(6):80-87.

Accepted 8 November 2018 